\title{
Elderly people as object of social work
}

\author{
Lilya Kemalova ${ }^{1, *}$, and Marina Nikonorova ${ }^{1}$ \\ ${ }^{1}$ Kerch State Maritime Technological University, 82, Ordzhonikidze str., 298309, Kerch, Russia
}

\begin{abstract}
The article accentuates the relevance of social work with elderly as one of the unprotected categories of people. It was noted that after termination of active work older people need assistance in the period of adaptation to new conditions as their lifestyle changes, their social connections are lost, they have feeling of loneliness and lack of being relevant. The basic directions, forms and methods of social work with older people are considered in this article.
\end{abstract}

\section{Introduction}

The problems of aging and the socio-psychological problems of older people in modern science are widely disclosed: Akimenko A [1], Allyson Lipp. [2], Bakanova A. [3], Barrett A.E. [4], Henricksen A., Stephens C. [5], Katz S. [6], Levinson R. [7]. Lovenstein A., Katz R., Gur-Yaish N. [8], Cramer P. [9], Kuziner E. [10], Kuznetsova L., Chebotarev V. [11], Melekhin A. [12], Sergienko E.A. [13], Nadasen K. [14], Novak M. [15], Pesina E. [16],Pit S, Byles J. [17], Schlafer M., Shippee T. [18], Schoppe S. [19], Suslova T. [20], Tolstykh N. [21], Torres S. [22], Venn S. [23] and etc. Elderly people are one of the least protected social groups which needs support and help from society and the state. Changes in the social status of a person in old age, caused primarily by the cessation of active work, the transformation of value guidelines, lifestyle, communication, and the emergence of various difficulties, both in social and psychological adaptation to new conditions, necessitates the development and implementation specific approaches, forms and methods of social work with older people.

Objective: to characterize the main directions, forms and methods of social work with the elderly.

\section{Problem raising}

An elderly person is a person who is at the final stage of his life, when changes occur at the physiological, psychological and social levels, which leads to the accentuation of certain character traits. According to most scientists, advanced age lasts about 10-15 years and ranges from age 60 to 75 years. The lower border of old age is at 55-60 years. The upper limit of elderly age (the beginning of old age) falls according to many scientists on 70-75 years.

\footnotetext{
* Corresponding author: kemalova@yandex.ru
} 
Characteristic features of this age are: a decrease in psychophysical capabilities (such as working capacity, endurance, attention and memory), a gradual withdrawal from an active social life, a feeling of being unneeded, loss of relatives or friends, loneliness, awareness of the approaching end of life. Elderly people experience a feeling of low value, self-doubt and dissatisfaction with oneself.

These characteristics of older people are associated with problems that they face due to their age. First of all, health and physical well-being are highlighted as main problems. Among elderly people the functioning of sensory systems is affected: hearing, vision, taste and smell, slowing down of reactions, negative changes in adaptive abilities and decreased mobility. Premature aging of the body can cause serious diseases - hypertension, atherosclerosis, metabolic disorders and others. For most people of advanced years typical are anxiety, neurotic depression, frustration, asthenia, a hysterical type of response and autonomic disorders.

Another important problem of elderly people are financial problems: more and more money have to be spent on medical care, drugs and health. The financial well-being of elderly has a special coloring. On the one hand, there is no longer a goal to be rich in order to meet prestige indicators and occupy a certain place on the social ladder. On the other hand, maintaining the existing financial condition may be a factor of influencing the selfesteem of an older person. However, these things concern a not very large quantity of financially wealthy people. Another layer are elderly whose main income was only salary and which significantly decreased with the person's retirement. For these people financial well-being is not a synonym for status, but a real issue of survival.

Besides financial and psychological age-related problems older people also face social problems. They are related to the fact that older people have to free up social positions for new generations. Older people do not notice that they are becoming less productive, so they feel injustice when they have to give way to young people. Stability and confidence in the future disappears. There is instead more space for uncertainty and fear of a new day. The situation is complicated by the fact that modern society is filled with many negative stereotypes in perception of old age and negative attitude towards elderly people. Aging is identified with a decrease in activity, a limitation of social competence and a need for help. An aging person is given the image of a redundant member of society. Recently the concept of "ageism", which was introduced by the American researcher R. Butler, is increasingly used. Ageism breeds discrimination, which is unacceptable for a developed state of the 21 st century. It involves the perception of older people as intellectually untenable, old-fashioned in their views, characterized by the contempt of the young and strong for the old and weak. The basis of this opinion is the young man's fear of old age and death [24].

Thus, a decrease in physical activity, social mobility and financial security, a change in the structure of communication lead to an exacerbation of feelings of loneliness. It often causes depression and various deformations of character. As a result, an increase in negative character traits (irritation, tearfulness, bitterness, etc.), a feeling of rejection. All this creates a lot of problems and requires attention not only from psychologists, but also from social workers.

Social work with older people is a special process of focused practical activity, carried out by professionally trained specialists in order to effectively resolve individual problems of older people who find themselves in difficult life situations. Social work with the elderly has its own specifics and is aimed at identifying people who need help at home or in special social service institutions. In addition, the social worker must conduct a diagnosis and analyze the social environment in which older people live, determine their needs.

Studying the problems of elderly people allows us to choose the direction of work with them. For example, social service and social welfare for elderly citizens. They involve helping older people by social workers in obtaining pensions, various benefits, serving the 
elderly and disabled in special institutions and helping the homeless. Forms of social services include social assistance at home, semi-stationary and stationary services, social and advisory support.

Another area of social work is the social care of older people. It is carried out in stationary conditions, in nursing homes for elderly and disabled, where elderly people get assistance in the socio-psychological adaptation to new conditions. In such institutions there have been created not only conditions for living, but there are also carried out activities of social, social, labor and medical rehabilitation, organization of leisure and recreation. In the regions of Russia there are 674 state-owned homes for elderly and disabled with capacity for 92.8 thousand people

In addition to these areas, a special role is played by medical and social rehabilitation, as a set of measures aimed at restoring, strengthening the health, preventing diseases and restoring the ability to social functioning. The way of rehabilitation depends on health conditions and on type of pathology.

An equally important area is the provision of psychological and social assistance. The main task is social adaptation and the process of the individual's active adaptation to the conditions of the social environment. To work in this direction it is necessary to organize consultative psychological assistance, various activities for organizing leisure activities for older people, custody of families with elderly people.

A social worker is dedicated to provide assistance to this category of people in all areas by using various methods of social work [25].

The methods of social work with elderly people include:

- organizational: assistance to citizens in obtaining various types of social services and social assistance;

- socio-psychological: providing of psychological support to older people through psychological correction; attracting elderly people to participate in special trainings aimed at increasing of psychological stability and adaptation; providing of psychopreventive activities for most successful adaptation to society;

- socio-economic: assistance in obtaining of financial assistance available for an elderly person (benefits, allowances, compensations, other payments);

- social and household: purchase and home delivery of food and other goods to citizens; assistance in cleaning the premises, dry cleaning, washing; assistance in cooking, payment of bills;

- $\quad$ socio-legal: assistance in paperwork; assistance in obtaining legal support, in protecting the rights and interests of clients;

- socio-medical: formation of a healthy lifestyle, conducting of medical, preventive, sanitary and hygienic actions; maintaining people's health;

- socio-pedagogical: attracting older people to cognitive activity, activating creative potential and maintaining a positive attitude to life; conducting educational lectures, events, round tables, discussions on given topics;

- rehabilitational: rendering services to people who are not able to self-service: jointly conducting medical and health-improving actions; attracting elderly people to participate in sports sections and performing a set of physical exercises aimed at improving health; conducting aromatherapy, music therapy, isotherapy, cinema therapy etc.

Knowledge of main problems of elderly allows us to determine the direction and methods of social work with them, helps to achieve the effectivity of work with this category of the people.

During our survey we have identified main problems of older people in Kerch with the purpose to understand the effectiveness of social work with them. The sampling consisted 
of 20 elderly people, customers of the Social Service Center. 13 of them were women and 7 - men (Figure 1). The age range was $60-72$ years.

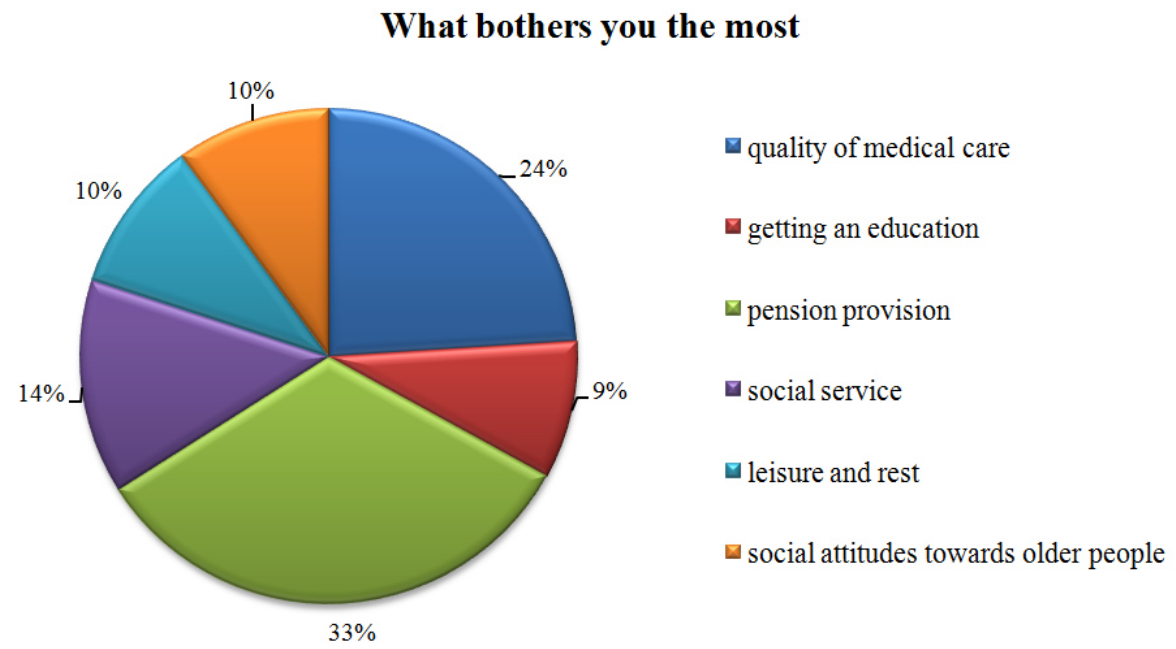

Fig. 1. Matters of concern of elderly people who participated in the survey.

To the question about worries of older people $33 \%$ of respondents said that they were concerned about pension provision, $24 \%$ were worried about the quality of medical care. Social services worried about $14 \%$ of respondents. The least worrying were rest and recreation $(10 \%)$, their role in society $(10 \%)$ and educational programs for older people (9\%) (Fig. 1).

To the question: "What kind of social support services are provided to you, in addition to pension and social welfare?"

\section{What social services do you receive in addition}

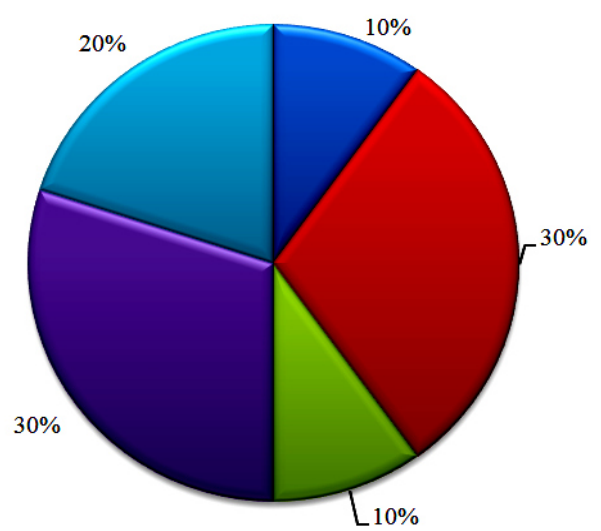

targeted social assistance

stay in sanatoriums

$\square$ free provision of medicines

$\square$ free dental prosthetics

$\square$ I do not receive social services

Fig. 2. Social support services provided to elderly people.

$10 \%$ of respondents answered: "Free medical care", 30\% - "Free dental prosthetics", $10 \%$ - "Targeted social assistance", 30\% - "Rehabilitation and treatment in sanatoriums". $20 \%$ of respondents noted that these social support measures were not provided (Fig. 2). 
During discussion about these issues the clients of the KSSC admitted that receiving this or that type of additional assistance is a long and difficult process, which is rarely going without any difficulties. For example, the right to receive a targeted social assistance is exclusively reserved for elderly citizens and people with special needs who are in difficult life situations (unemployment, disability, loneliness, etc.). Additional rule - their average family income can not exceed 1.5 times the size of living wage per capita. A citizen has to prepare a stack of documents and pass them to the social service authority. Within 30 calendar days a decision is made about the provision or refusal of targeted social assistance.

Only those people who have medical indications for treatment (diseases of the cardiovascular system, musculoskeletal system, gastrointestinal tract, etc.) have right to get free rehabilitation and treatment in sanatoriums. Following documents need to be collected and provided: passport, pension certificate, employment record, medical certificate with statement of the right to receive appropriate treatment, a certificate about the amount of the pension and a spa card. The situation is complicated by the fact that pensioners often have to wait for several years for receiving social assistance.

When asked about what services are being provided by the Center for Social Services, respondents noted: socio-medical (40\% of respondents), household services $(25 \%)$, sociopsychological (20\% of respondents), socio-legal (10\%), social pedagogical (5\%) (Fig. 3). Thus, the entire service sector is involved.

\title{
What services are provided to you at the State Budgetary Institution of the Republic of Crimea "KCCO of Kerch"?
}

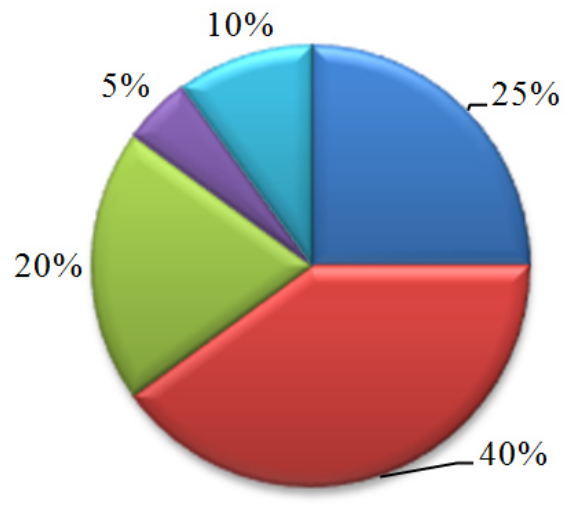

\author{
回 socially-household \\ 四 socially-medical \\ ⿶ socially-psychological \\ $\square$ socially-pedagogical \\ socially-legal
}

Fig. 3. Services provided to citizens in KSSC.

The results of the survey allow us to conclude that in its practical activities to improve the quality of life of the elderly the Kerch Social Service Center successfully combines the usage of traditional technologies (cash payments; subsistence provision; services and benefits; stationary and non-stationary types of services) and innovative technologies (cinema therapy, bibliotherapy, local history lessons, "active longevity"). This helps older people to adapt to changing conditions and form a positive picture of life in old age.

\section{Summary}

Firstly, it was displayed that current living situation of elderly, the totality of their problems makes older people to one of the most vulnerable categories of people. They require increased attention from the state in sense of becoming a main object of social work. 
Therefore, in Russia currently runs a large network of social institutions for this category of citizens. In particular there are boarding houses, geriatric pensions, territorial centers of social services for pensioners, as well as special residential buildings with a range of provided social services and 24/7 medical care.

We identified the main areas of social work with the elderly: social welfare and services; social care; medical and social rehabilitation; psychological assistance.

Based on the data about the methods and forms of assistance in Kerch Social Service Center, we have analyzed the role of this institution in improving the quality of life of older people. Social services provided in this institution help to cower the most important needs of elderly, improve their quality of life and ensure well-being in all areas of human life.

\section{References}

1. A. Akimenko, Izvestiya Saratov University. Series Acmeology Education 2 (2016) doi: https://doi.org/10.18500/2304-9790-2016-5-2-151-156

2. A. Lipp, International Journal of Multiple Research Approaches 11(1) (2007) doi: 10.5172/mra.455.1.1.18

3. A. Bakanova, Cultural-historical psychology 11.1 (2015) doi: 10.17759 / chp. 2015110103

4. A. Barrett, Jornal of Aging Studies 19, 2 ( 2005) doi:10.1016/j.jaging.2004.05.002

5. A. Henricksen, C. Stephens, Ageing International 35, 4 (2010) doi:10.1007/s12126010-9059-y

6. S. Katz, Recherchés Sociologies et Anthropologies 44, 44-1 (2013)

7. R. Levinson, FCPE Newsletter 8, 2 (2005) http://fcpe.adelphi.edu/files/2014/04/ Spring-2005-Issue-8.pdf

8. A. Lovenstein, R. Katz, N. Gur-Yaish, Journal of Social Issues 63, 4 (2007) doi:10.1111/j.1540-4560.2007.00541.x

9. P. Cramer, Journal of Research in Personality 37(1) (2003) doi:10.1016/S00926566(02)00528-7

10. E. Kuziner, International Research Journal 11(65) (2018) doi: 10.23670 / IRJ.2017.65.156

11. L. Kuznetsova, V. Chebotarev, Young scientist 5 (2014) https://moluch.ru/archive/64/10171/

12. A. Melekhin, Modern foreign psychology 5, 1 (2016) doi: 10.17759 / jmfp.2016050107

13. A. Melekhin, E. Sergienko, Social Psychology and Society 6, 4 (2015) doi: 10.17759.2015060405)

14. K. Nadasen, Journal of Women \& Aging 20, 3-4 (2008) doi:10.1080/08952840801985060

15. M. Novak, Issues in Aging (Pearson, Boston, 2011)

16. E. Pesina, Modern Research on Social Problems 9, 12 (2018) doi : 10.12731/22187405-2018-12-207-228

17. S. Pit, J. Byles, Journal of Womens Health 21 (2012)

18. M. Schlafer, T.Shippee, Social Psychology Quarterly 73, 3 (2010) doi:10.1177/0190272510379751 
19. S. Schoppe, A. Bauman, F. Bull, International review of national physical activity policy: A literature review: Centre for Physical Activity and Health (Centre for Physical Activity and Health, Australia,2004)

20. T. Suslova, Social activity of a personality as a determinant of positive adaptation and a fulfilling life in retirement age (2017) doi: 10.17759 / jmfp.2017060307

21. N. Tolstykh, Advisory psychology and psychotherapy 23, 4 (2015) doi: 10.17759 / cpp.2015230402

22. S. Torres, G. Hammarstrom, Journal of Aging Studies 20, 4 (2006) doi:10.1016/j.jaging.2005.11.001

23. S. Venn, S. Arber, Ageing Society (2011) doi 0421100116/0005.

24. R. Butler, Social technologies in public administration (Unity-Dana, Moscow, 2007)

25. N. Logunova, L. Aleksahina, S. Chernyi, International Conference "Quality Management, Transport And Information Security, Information Technologies" (IT\&QM\&IS) (2017) doi: 10.1109/itmqis.2017.8085781 